\title{
Er-Coupled Si Nanocluster Waveguide
}

\author{
Nicola Daldosso, Daniel Navarro-Urrios, Mirko Melchiorri, Cristina García, Paolo Pellegrino, Blas Garrido, \\ Cinzia Sada, Giancarlo Battaglin, Fabrice Gourbilleau, Richard Rizk, and Lorenzo Pavesi
}

(Invited Paper)

\begin{abstract}
Rib-loaded waveguides containing $\mathrm{Er}^{3+}$-coupled $\mathrm{Si}$ nanoclusters (Si-nc) have been produced to observe optical gain at $1535 \mathrm{~nm}$. The presence of Si-nc strongly improves the efficiency of $\mathrm{Er}^{3+}$ excitation but may introduce optical loss mechanisms, such as Mie scattering and confined carrier absorption. Losses strongly affect the possibility of obtaining positive optical gain. Si-nc-related losses have been minimized to $1 \mathrm{~dB} / \mathrm{cm}$ by lowering the annealing time of the $\mathrm{Er}^{3+}$-doped silicon-rich oxide deposited by reactive magnetron cosputtering. Photoluminescence (PL) and lifetime measurements show that all $\mathrm{Er}^{3+}$ ions are optically active while those that can be excited at high pump rates via Si-nc are only a small percentage. $\mathrm{Er}^{3+}$ absorption cross section is found comparable to that of $\mathrm{Er}^{3+}$ in $\mathrm{SiO}_{2}$. However, dependence on the effective refractive index has been found. In pump-probe measurements, it is shown how the detrimental role of confined carrier absorption can be attenuated by reducing the annealing time. A maximum signal enhancement of about 1.34 at $1535 \mathrm{~nm}$ was measured.
\end{abstract}

Index Terms-Er amplifier, Si nanocluster, silicon photonics, waveguides.

\section{INTRODUCTION}

$\mathbf{O}$ VER the last 20 years, optical fiber has become the dominant long-distance transmission medium for data communication. Although signal losses in optical fibers are now close to the theoretical limit of $0.1 \mathrm{~dB} / \mathrm{km}$ at $1.55 \mu \mathrm{m}$, and pulse broadening (dispersion) can be controlled effectively, signal regeneration (amplification) is still a necessity. This is conventionally done by using erbium-doped fiber amplifiers (EDFAs), the success of which has set the standard for the optical communication wavelength. While EDFAs are well established in long-haul

Manuscript received November 15, 2005; revised September 1, 2006. This work was supported in part by the European Commission via Project SINERGIA (FP5-29650) and in part by Fondo per gli Investimenti per la Ricerca di Base (FIRB) and Provincia Autonomia di Trento (PAT).

N. Daldosso, D. Navarro-Urrios, and L. Pavesi are with the Nanoscience Laboratory, Department of Physics, University of Trento, 38050 Trento, Italy (e-mail: daldosso@science.unitn.it; navarro@science.unitn.it; pavesi@science.unitn.it).

M. Melchiorri was with the Nanoscience Laboratory, Department of Physics, University of Trento, 38050 Trento, Italy. He is now with the Istituto Trentino di Cultura, IRST, 38050 Trento, Italy (e-mail: melchiorri@itc.it).

C. García, P. Pellegrino, and B. Garrido are with Enginyeria i Materials Electronics (EME), Departament d'Electrònica, Universitat de Barcelona, 08028 Barcelona, Spain (e-mail: nablas_realm@yahoo.es; paolo@el.ub.es; blas@el.ub.es).

C. Sada is with the Dipartimento di Fisica, Università di Padova, I-35131 Padova, Italy (e-mail: sada@padova.infm.it).

G. Battaglin is with the Dipartimento di Chimica Fisica, Università di Venezia, I-30123 Venice, Italy (e-mail: battagli@unive.it).

F. Gourbilleau and R. Rizk are with Structure des interfaces et Fonctionnalité des Couches Minces (SIFCOM), Unité Mixte de Recherche (UMR), Centre National de la Recherche Scientifique (CNRS) 6176, Ecole Nationale Superieure d'Ingenieurs de Caen et Centre de Recherche (ENSICAEN), 14050 Caen, France (e-mail: fabrice.gourbilleau@ensicaen.fr; richard.rizk@ensicaen.fr).

Digital Object Identifier 10.1109/JSTQE.2006.885141 transmission, reducing their size and cost for integration in local area networks (LANs) presents major difficulties: Ion pair interactions, combined with the small excitation cross section of the $\mathrm{Er}^{3+}$ ion $\left(10^{-21} \mathrm{~cm}^{2}\right)$ impose the use of long lengths of lightly doped fiber. Moreover, high-power (and therefore expensive) laser diodes tuned to specific $\mathrm{Er}^{3+}$ electronic transitions are required as pump sources. Both these are fundamental physical limitations inherent in the material. A new gain medium that enables broadband optical or electrical excitation of rare earth ions and provides order-of-magnitude enhancements in effective absorption cross sections, with corresponding reductions of amplifier dimensions and cost, would have a big impact on optical amplification and optical networking architectures.

$\mathrm{Si}$ nanoclusters (Si-nc) in silica matrices have proved to be efficient sensitizers for $\mathrm{Er}^{3+}$ [1] because 1) the effective absorption cross section is about $10^{-16} \mathrm{~cm}^{2}(488 \mathrm{~nm})$ at low pumping power [2], [3], which is of the same order as that of Si-nc absorption (thus inferring an efficient energy transfer from Si-nc to $\mathrm{Er}^{3+}$ ions) and orders of magnitude larger than the intrinsic absorption cross section of $\mathrm{Er}^{3+}$ in $\mathrm{SiO}_{2}$ (about $8 \times 10^{-21}$ $\mathrm{cm}^{2}[4]$ ); 2) their absorption band is broad and in the UV-Vis range, where very cheap diode lasers or light-emitting diodes (LEDs) are available; and 3) the effective refractive index of the composite material is increased by the presence of Si-nc at values larger than that of silica, thus allowing good light confinement. Moreover, encouraging results on electroluminescence in such systems open the possibilities of electrically pumped optical amplifiers [5]. In this way, the functionality of Si electronics might be merged with the optical data transmission capabilities of silica fibers to yield optical integrated circuits within complimentary metal-oxide-semiconductor (CMOS) microcircuits. One enabling device would be an electrically pumped erbiumdoped waveguide amplifier (EDWA) operating at $1.55 \mu \mathrm{m}$.

In $\mathrm{Er}^{3+}$-coupled Si-nc waveguides, $\mathrm{Er}^{3+}$ ions present quantum efficiencies greater than $60 \%$ and Si-nc-to- $\mathrm{Er}^{3+}$ transfer rates higher than $1 \mu \mathrm{s}^{-1}$ by pumping at $488 \mathrm{~nm}$ at low fluxes [6]. Except for the encouraging results of Shin and coworkers [7], [8], strong detrimental processes such as cooperative up-conversion and excited state absorption (ESA) [9] related to the Er content, Auger nonradiative de-excitations and confined carrier absorption (CA) within the Si-nc are preventing net optical gain when reaching high pumping fluxes [10], [11]. It is worth noting that CA has not only the effect of introducing a pump-power-dependent loss mechanism at the signal wavelength but also that of decreasing the effective excitation cross section of $\mathrm{Er}^{3+}$ by introducing a competing mechanism for Sinc de-excitation. The full comprehension of the energy transfer mechanism from Si-nc to $\mathrm{Er}^{3+}$ is still under debate [12], [13], 


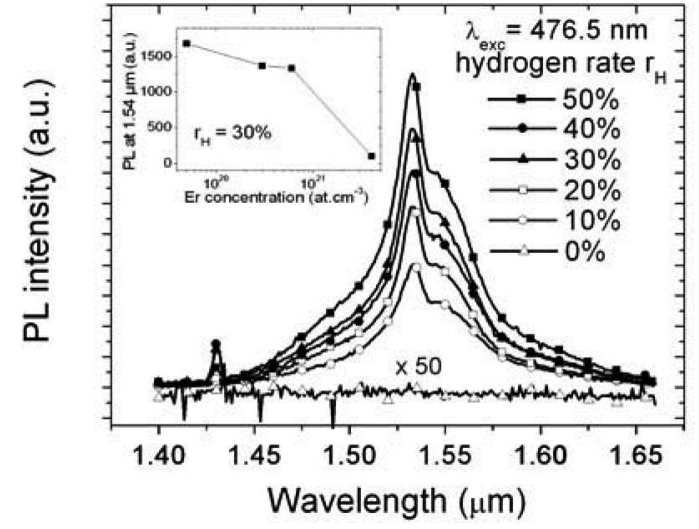

Fig. 1. Evolution of the $\mathrm{Er}^{3+}$ emission as a function of the hydrogen rate in the plasma. The emission at $1.54 \mu \mathrm{m}$ versus the Er concentration in the films grown with a hydrogen rate of $30 \%$ are shown (inset).

and the optimization of the material in terms of density and size of Si-nc and of $\mathrm{Er}^{3+}$ content is to be completed [14]. At low excitation rates, $\mathrm{Er}^{3+}$ content should not exceed $2 \times 10^{20}$ to $4 \times 10^{20} \mathrm{~cm}^{-3}$ to avoid clustering, cooperative up-conversion, and ESA [15]. The ratio between Si-nc and $\mathrm{Er}^{3+}$ ions is still to be optimized: High density of Si-nc is desired to efficiently pump all the $\mathrm{Er}^{3+}$ ions, but this high density will in turn cause a significant $\mathrm{CA}$ and will affect optical losses.

In this experimental work, we have performed a first study in order to optimize processing conditions to maximize the coupling between Si-nc and $\mathrm{Er}^{3+}$ ions and the signal enhancement in a strongly pumped ridge waveguide structure.

\section{FABRICATION}

A series of Er-doped Si-rich silica layers were deposited by reactive magnetron sputtering, and then thermally treated under various conditions to reach an optimized composition of the material in terms of efficient and high rate coupling between $\mathrm{Si}$-nc and $\mathrm{Er}^{3+}$ ions. The Er content was varied and adjusted through the number of the cosputtered $\mathrm{Er}_{2} \mathrm{O}_{3}$ pellets placed on top of the silica target, while the $\mathrm{Si}$ excess was monitored by the hydrogen rate $r_{\mathrm{H}}$ (mixed to argon), considering the reducing ability of hydrogen toward the oxygen originating from the silica target [16], [17]. The layers were deposited on nonintentionally heated silica-capped $\mathrm{Si}$ substrates with a power density of $0.75 \mathrm{~W} / \mathrm{cm}^{2}$. They were subsequently annealed under Ar or $\mathrm{N}_{2}$ flux at various temperatures (between $700^{\circ} \mathrm{C}$ and $1100^{\circ} \mathrm{C}$ ) for different durations.

The optimization of the material for a maximum $\mathrm{Si}-\mathrm{nc} / \mathrm{Er}^{3+}$ coupling in terms of photoluminescence (PL) efficiency was achieved by successive steps. First, the effect of the dilution of the Ar plasma with $\mathrm{H}_{2}$ was studied by varying the hydrogen rate $r_{\mathrm{H}}$ between $0 \%$ and $50 \%$ for samples annealed at $1100^{\circ} \mathrm{C}$ during $1 \mathrm{~h}$. Fig. 1 shows the PL spectra of the deposited films using a nonresonant 476.5-nm excitation line, which ensures that the emitting $\mathrm{Er}^{3+}$ ions are only those excited through the $\mathrm{Si}$-nc. This is confirmed by the absence of $\mathrm{Er}^{3+}$ emission when the sample is free from $\mathrm{Si}$ excess, i.e., when fabricated with no hydrogen

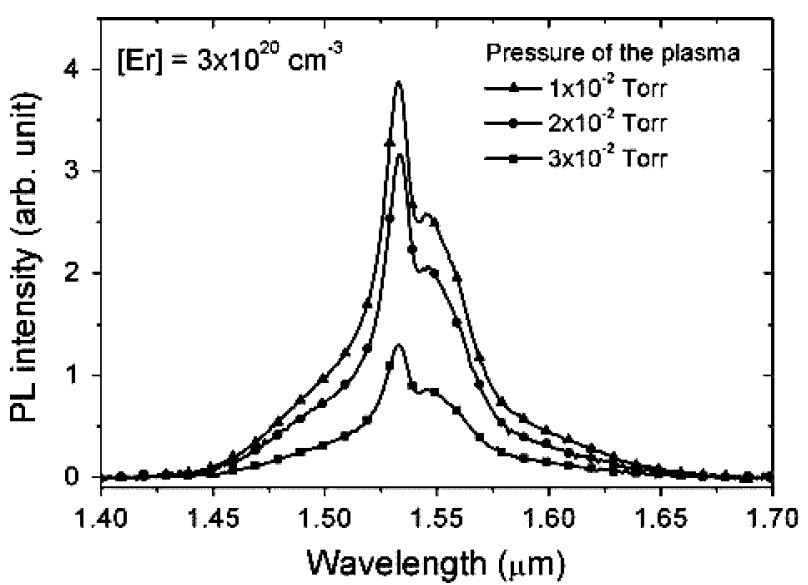

Fig. 2. Effect of the deposition parameter (plasma pressure) on the emission properties of the $\mathrm{Si}-\mathrm{nc} / \mathrm{Er}^{3+}$ system containing a density of $\mathrm{Er}$ of $3 \times 10^{20} \mathrm{~cm}^{-3}$.

in the plasma $\left(r_{\mathrm{H}}=0 \%\right)$. It should be noted that the increase of the $r_{\mathrm{H}}$ parameter favors the coupling rate between Si-nc and $\mathrm{Er}^{3+}$ ions, since the $\mathrm{Er}^{3+}$ emission is increased three times between $r_{\mathrm{H}}=10 \%$ and $50 \%$. As the variation of the hydrogen rate does not influence the Si excess, which remains constant at about 11 at\% [18], one can suggest that such PL behavior is due to an increased number of Si-nc nucleation sites. In fact, since the total Si content stays constant, an increased $\mathrm{Er}^{3+}$ emission can be explained by an increased density of smaller Si-nc. This should favor the coupling between Si-nc and $\mathrm{Er}^{3+}$ ions.

The increase of the Er content in the film (Fig. 1, inset) leads to a decrease of about $20 \%$ of the PL intensity at $1.54 \mu \mathrm{m}$ between $5 \times 10^{19}$ and $6 \times 10^{20} \mathrm{~cm}^{-3}$ and has a real detrimental effect for Er concentration higher than $7 \times 10^{20} \mathrm{~cm}^{-3}$. This decrease can be attributed to a possible $\mathrm{Er}^{3+}$ clustering and/or concentration quenching.

To overcome the PL limitation occurring for the Er concentration of $3 \times 10^{20} \mathrm{~cm}^{-3}$ and facilitate an increase of the coupling between Si-nc and $\mathrm{Er}^{3+}$ ions, some fabrication parameters have been changed. One of them is the total pressure of the $\mathrm{Ar}+\mathrm{H}_{2}$ mixture plasma that was reduced from $4.5 \times 10^{-2}$ to $1 \times 10^{-2}$ torr. The typical evolution of the PL emission of the deposited films with the plasma pressure is shown in Fig. 2 for an $r_{\mathrm{H}}=30 \%$ and an Er density of $3 \times 10^{20} \mathrm{~cm}^{-3}$. The decrease of the pressure of the plasma leads to the concomitant decrease of the deposition rate of the species. Thus, the enhancement of the PL emission at $1.54 \mu \mathrm{m}$ can be attributed to a better oxide quality and coupling between the Si-nc and $\mathrm{Er}^{3+}$ ions.

Another parameter studied was the annealing temperature. Fig. 3 shows that the maximum intensity of the $\mathrm{Er}^{3+}$ emission is reached for an annealing temperature of $900^{\circ} \mathrm{C}$ during $1 \mathrm{~h}$ for a typical $r_{\mathrm{H}}$ value of $50 \%$. Higher temperature leads to a decrease of the $\mathrm{Er}^{3+}$ emission. The evolution of the $\mathrm{Er}^{3+}$ lifetime, shown in the inset of Fig. 3, shows a continuous increase with the annealing temperature attributed to a recovery of the nonradiative recombination centers. Moreover, such behavior allows excluding defect formation to justify the decrease of the PL for annealing temperatures higher than $900^{\circ} \mathrm{C}$. These evolutions 


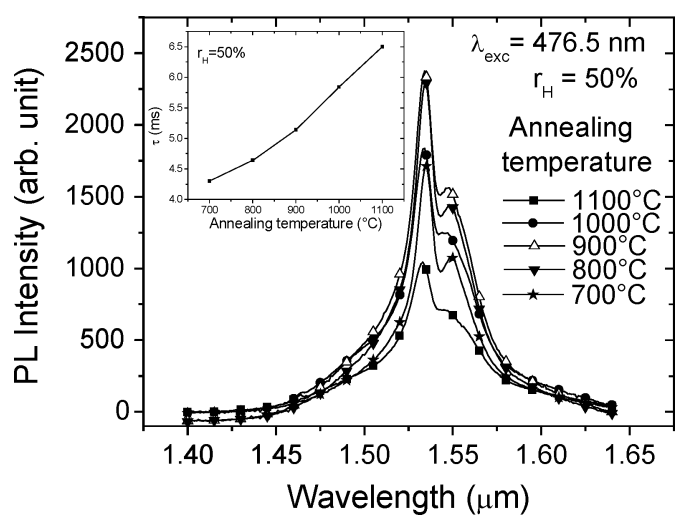

Fig. 3. Evolution of the $\mathrm{Er}^{3+}$ emission for a hydrogen rate of $50 \%$ as a function of the annealing temperature. The values of the lifetime are shown (inset)

TABLE I

SAMPLE PARAMETERS

\begin{tabular}{ccccccc}
\hline \hline Sample & $\begin{array}{c}\text { Annealing } \\
\text { time } \\
(\mathrm{min})\end{array}$ & $\begin{array}{c}\text { Si excess } \\
(\text { at. \%) }\end{array}$ & $\begin{array}{c}\text { Er content } \\
\left(\mathrm{x} 10^{20} \mathrm{~cm}^{-3}\right)\end{array}$ & $\begin{array}{c}\text { Core layer } \\
\text { thickness (nm) }\end{array}$ & $\begin{array}{c}n \\
\text { at } 632.8 \mathrm{~nm}\end{array}$ & $\begin{array}{c}n \\
\text { at } 1480 \mathrm{~nm}\end{array}$ \\
\hline $\mathrm{A}$ & 240 & $6-7^{*}$ & $3 *$ & 750 & $1.61 \pm 0.01$ & - \\
$\mathrm{B}$ & 60 & 7 & $4 \pm 0.1$ & 750 & 1.545 & 1.531 \\
$\mathrm{C}$ & 30 & 7 & $5.4 \pm 0.2$ & 840 & 1.516 & 1.501 \\
$\mathrm{D}$ & 10 & 7 & $5.4 \pm 0.2$ & 840 & $1.48 \pm 0.01$ & 1.473 \\
$\mathrm{E}$ & 5 & 7 & $6.5 \pm 0.2$ & 890 & 1.468 & 1.460 \\
$\mathrm{~F}$ & 1 & 7 & $5.5 \pm 1$ & 880 & 1.463 & - \\
\hline \hline
\end{tabular}

evidence the critical role of this fabrication parameter in the coupling between $\mathrm{Si}-\mathrm{nc}$ and $\mathrm{Er}^{3+}$ ions through the distribution and the density of Si-nc in the film.

A detailed optimization of the material has been inspired by three recent findings: 1) the increasingly sensitizing effect of smaller Si-nc located below a critical distance from the neighboring ions [19]; 2) the optical loss induced by the parasitic carrier absorption [11]; and 3) the effect of annealing time on the emission properties of such Er-doped system [20]. Taking these results into account, slab waveguides have been fabricated with the core layer produced with a low plasma pressure, intermediate Er concentration, and high hydrogen rate to favor coupling between $\mathrm{Si}-\mathrm{nc}$ and $\mathrm{Er}^{3+}$ ions, and therefore, the $\mathrm{Er}^{3+}$ emission. Deposition was performed on a silicon wafer where a thick layer $(15 \mu \mathrm{m})$ of $\mathrm{SiO}_{2}$ was deposited. This layer acts as a cladding layer and ensures the optical isolation of the core layer with respect to the silicon substrate. A further $\mathrm{SiO}_{2}$ layer sputtered on top of the active core layer provides the top cladding and concludes the deposition process. After deposition, the waveguides are annealed at $900^{\circ} \mathrm{C}$ and, for a more advanced optimization, the treatment duration is varied: annealing times of $240,60,30,10,5$, and $1 \mathrm{~min}$ have been used with the aim of enhancing the sensitizing effect of Si-nc on $\mathrm{Er}^{3+}$ emission and lowering both the optical losses and the confined carrier absorption. Main slab waveguide parameters are reported in Table I. For the first set of experiments, we will refer to the waveguides as samples.

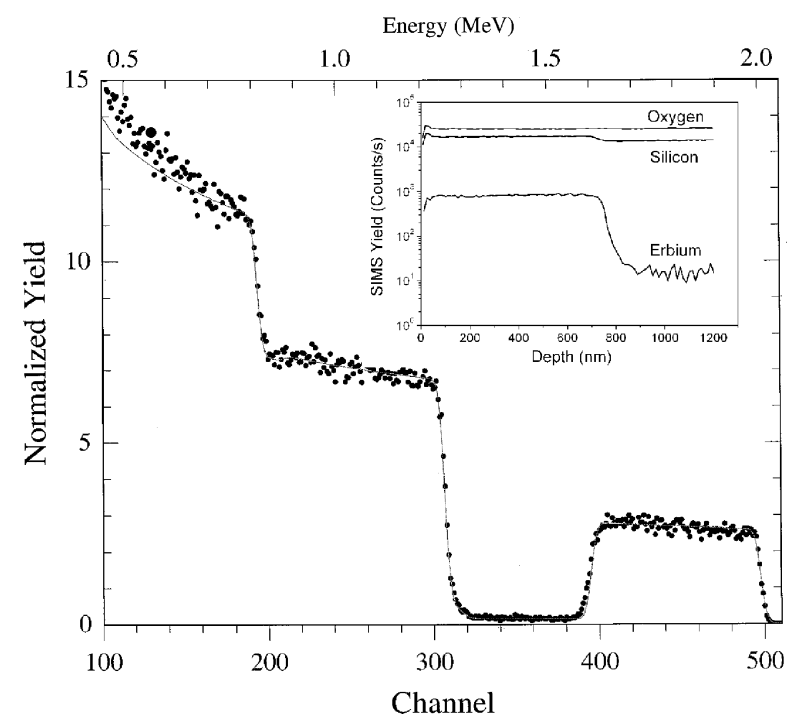

Fig. 4. RBS spectrum (full points) and the relative simulation (line) of the sample composition. SIMS profiles of $\mathrm{O}, \mathrm{Si}$, and Er content are shown (inset).

\section{SAMPLE CHARACTERIZATION}

\section{A. Structural Characterization}

By the use of secondary ion mass spectroscopy (SIMS) and Rutherford backscattering spectroscopy (RBS), the Si excess and the Er content profile have been determined. SIMS measurements were carried out by means of an IMS 4f mass spectrometer using a $14.5-\mathrm{KeV} \mathrm{Cs}^{+}$primary beam and by negative secondary ion detection. The charge build up, while profiling the insulating samples, was compensated by an electron gun without the need to cover the surface with a metal film. The erosion speed was evaluated by measuring the depth of the erosion crater at the end of each analysis. The RBS measurements were performed using a ${ }^{4} \mathrm{He}^{+}$beam (energy $2 \mathrm{MeV}$ ) incident at $160^{\circ}$.

Fig. 4 shows the SIMS and RBS results for sample B-60' as an example. The SIMS analysis shows that the erbium, oxygen, and silicon contents are constant through the core layer within $5 \%$, and that no segregation peak is present at the interface with the buffer layer. The core layer thickness was estimated to be $750 \pm 50 \mathrm{~nm}$. The result of the simulation is a single layer with constant $\mathrm{Er}, \mathrm{Si}$, and $\mathrm{O}$ concentrations, in agreement with the SIMS measurements. In particular, the Si excess is about $7 \%$ for this sample. By combining the SIMS and RBS measurements, the concentration of $\mathrm{Er}^{3+}$ ions has been found to be close to $4 \times 10^{20} \mathrm{at} / \mathrm{cm}^{3}$. Si excess and Er content for the whole set of samples are reported in Table I. Samples were annealed at the same temperature for different annealing times.

\section{B. Optical Characterization}

M-lines spectroscopy was performed by prism-coupling to measure the refractive index of the core layer at two different wavelengths $(632.8 \mathrm{~nm}$ and $1.480 \mu \mathrm{m})$. In the visible spectrum, a $\mathrm{Si}$ detector was used, while in the nearinfrared (NIR) one, a cooled Ge detector was exploited. The 


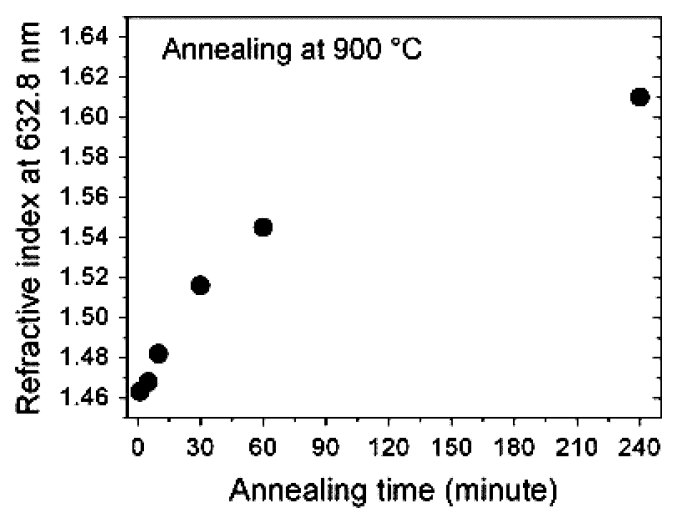

Fig. 5. Refractive index measured at $632.8 \mathrm{~nm}$ as a function of the annealing time for a fixed annealing temperature of $900{ }^{\circ} \mathrm{C}$.

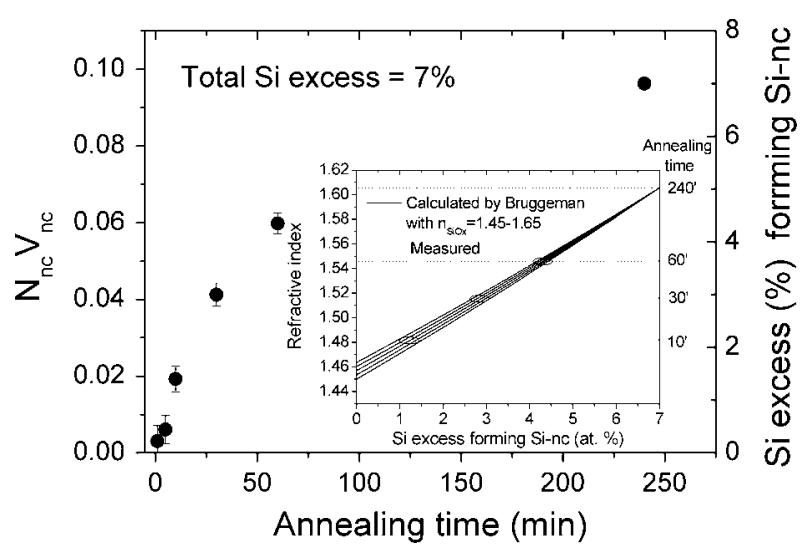

Fig. 6. Calculated excess Si that segregates into Si-nc as a function of the annealing time. The refractive indexes measured at $632.8 \mathrm{~nm}$ for different annealing times (horizontal dashed lines) and calculated using Bruggeman approximation are shown (inset).

measurements were performed first with a prism with refractive index $n_{\mathrm{p}}=1.7347$, and then repeated with a rutile prism $\left(n_{\mathrm{o}}=2.5839, n_{\mathrm{e}}=2.8657\right)$.

The refractive index $n$ of the samples increases as the annealing time lengthens (Fig. 5). It is worth noting that the sample thickness (measured by SIMS) slightly decreases for prolonged annealing time, suggesting a slight densification of the layers with time.

Fig. 5 is interpreted as an increased clustering of $\mathrm{Si}$ when the annealing time increases. By using the Bruggeman effective medium approximation [21], [22], the composite material can be modeled by different structural phases. A system composed of $\mathrm{Si}$-nc embedded in $\mathrm{SiO}_{2}$ is able to reproduce the measured refractive index only for the sample annealed for $240 \mathrm{~min}$. In this case, the measured refractive index of about 1.61 is well reproduced by calculations when the $\mathrm{Si}$ excess is $7 \%$, which matches the value found by SIMS (Fig. 6, inset). This confirms that the phase separation is almost complete in this case, as supposed for such a long annealing time. For shorter annealing times, this simple modeling fails. In fact, to take into account the fact that not all the excess silicon segregates into Si-nc and the presence of voids due to an incomplete densification, a substoichiometric defected silica phase $\mathrm{SiO}_{x}(x<2)$ has to

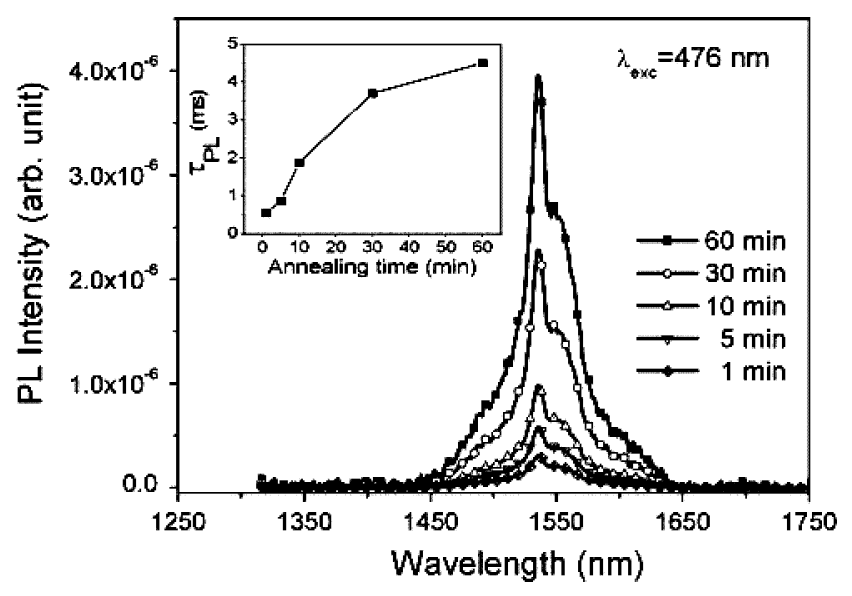

Fig. 7. PL spectra (normalized for sample thickness and Er content) and lifetime obtained under 476-nm excitation.

be considered. We have used a refractive index of 3.9 for $\mathrm{Si}-\mathrm{nc}$, 1.45 for $\mathrm{SiO}_{2}$, and between 1.45 and 1.65 for $\mathrm{SiO}_{x}$. From a fit of the data, we can deduce the $\mathrm{Si}$ in excess that segregates into $\mathrm{Si}$ nc: this amount grows as the annealing time increases (Fig. 6). A more detailed analysis can be found in [23]. It is worth noting that the dielectric where $\mathrm{Si}$-nc form is not a pure $\mathrm{SiO}_{2}$ for low annealing times $\left(<240^{\prime}\right)$, but it is still an $\mathrm{SiO}_{x}$ with some voids or defects. This, in turn, means that the $\mathrm{Er}^{3+}$ local environment is different from that of $\mathrm{Er}^{3+}$ in pure $\mathrm{SiO}_{2}$. The other point to be remembered is that if the Si-nc density can be considered constant and independent on the annealing time [26], and since the fit shows that the volumetric fraction of $\mathrm{Si}-\mathrm{nc}$ is increased by increasing the annealing time (Fig. 6), then the Si-nc mean size increases as the annealing time increases.

In a recent study [24], the refractive index of quantumconfined silicon has been found lower with respect to that of bulk silicon. In the present paper, however, the annealing temperature is such that only amorphous Si nanoclusters are created [15]. Amorphous Si has a refractive index larger than crystalline silicon [25], thus balancing the decreases due to quantum confinement. The final result is that a refractive index of 3.9 for the Si-nc fits the data.

The PL measurements were performed with a thermoelectrically cooled InGaAs photomultiplier, connected to a lock-in to ensure synchronous detection. The excitation was provided by the 476-nm line of the Ar laser, modulated with a mechanical chopper to a frequency of $11 \mathrm{~Hz}$. Fig. 7 shows the PL spectra as a function of the annealing time for the 476-nm excitation.

It appears that the longer the annealing times, the stronger the $\mathrm{Er}^{3+}$ emission. Since the emission cross sections of $\mathrm{Er}^{3+}$ decrease for long annealing times (see later and also in [26]), these data can be interpreted as an increased effective excitation cross section of the $\mathrm{Er}^{3+}$ when the $\mathrm{Er}^{3+}$ excitation is mediated by $\mathrm{Si}-\mathrm{nc}$. In fact, the improved oxide quality in lengthy annealed samples enhances PL $\mathrm{Er}^{3+}$ emission since fast nonradiative recombination paths are suppressed; moreover, up-conversion decreases with increasing annealing time (see later). However, the augmented size of Si-nc for long annealing times do not favor 
the coupling between $\mathrm{Er}^{3+}$ and $\mathrm{Si}$-nc due to carrier absorption as will be shown later.

The lifetime of the PL emission at $1.54 \mu \mathrm{m}$ for nonresonant 476-nm excitation, was measured by connecting an InGaAs photomultiplier and a digital oscilloscope. The time response of the system was about 80-90 $\mu$ s. We deemed this response sufficient for measuring the $\mathrm{Er}^{3+}$ lifetime in $\mathrm{SiO}_{x}$, as it is usually in the 4-5 ms range. The inset of Fig. 7 shows the time decay of the PL $\tau_{\mathrm{PL}}$ (measured at a photon flux density $\phi=10^{16} \mathrm{ph} / \mathrm{cm}^{2} \cdot \mathrm{s}$ ) as a function of the annealing time. The lifetime increases with the annealing time by almost one order of magnitude due to an environmental change of the materials surrounding the $\mathrm{Er}^{3+}$ ions which, besides reducing the number of defects in the matrix, causes a different local field and, hence, increased radiative lifetimes (see more in [28]).

\section{Excitation of Er ${ }^{3+}$ Ions}

Quantitative measurements of the photon flux emitted from the samples have been possible by using a reference sample whose emission has been independently evaluated and quantified. The sample used as reference was soda lime, 1.3-mm-thick sample supplied by Corning, doped with $\mathrm{Er}^{3+}$ to a density of $2 \times 10^{20} \mathrm{~cm}^{-3}$. This sample is thick enough for its emission under 488-nm excitation to be directly measured with a calibrated optical multimeter, coupled to an integrating sphere. Geometrical, absorption, and internal reflection effects were carefully considered in order to determine the actual emission of the sample. At a pump flux $\phi=1.3 \times 10^{20} \mathrm{ph} / \mathrm{cm}^{2} \cdot \mathrm{s}$, the emission of the reference sample was found to be $0.598 \mathrm{~mW}$, corresponding to a density of excited $\mathrm{Er}^{3+}$ ions $N=6.3 \times 10^{17} \mathrm{~cm}^{-3}$, which is quite close to the expected value calculated from

$$
N=N_{\mathrm{Er}} \sigma_{488} \tau_{\mathrm{PL}} \phi=4.2 \times 10^{17} \mathrm{~cm}^{-3}
$$

with the Er density $N_{\mathrm{Er}}=2 \times 10^{20} \mathrm{at} / \mathrm{cm}^{-3}$, the effective excitation cross section for 488-nm light $\sigma_{488}=2 \times 10^{-21} \mathrm{~cm}^{2}$, and the total lifetime $\tau_{\mathrm{PL}}=8 \mathrm{~ms}$.

Using the calibrated sample as a reference, we were able to determine the collection losses in our PL setup, which allowed the conversion of the photomultiplier signal into the emitted photon flux, which, in turn, is related to $N$ through

$$
\phi_{\text {emitted }}=\frac{N}{\tau_{\mathrm{Rad}}} d
$$

where $d$ is the layer thickness and $\tau_{\text {Rad }}$ is the radiative lifetime, which has a value of $18 \mathrm{~ms}$ in $\mathrm{SiO}_{2}$ [27]. The same value has been taken for $\mathrm{SiO}_{x}$, since it has been proved that it is only slightly modified by long annealing times [28].

The density of excited $\mathrm{Er}^{3+}$ in each sample is plotted as a function of the pump power in Fig. 8 for nonresonant 476-nm excitation. The total Er content for the various samples is reported in Table I. For sample B-60', the excited state population at the highest pump flux (about $5 \times 10^{20} \mathrm{ph} / \mathrm{cm}^{2} \cdot \mathrm{s}$ ) was below $1.4 \times 10^{19} \mathrm{~cm}^{-3}$, corresponding to only $3.2 \%$ of the total $\mathrm{Er}$ concentration, and clearly tending toward saturation. Similar values were reported by Wojdak et al. [14] for a sample grown by ion implantation. Extrapolating these curves allows the esti-

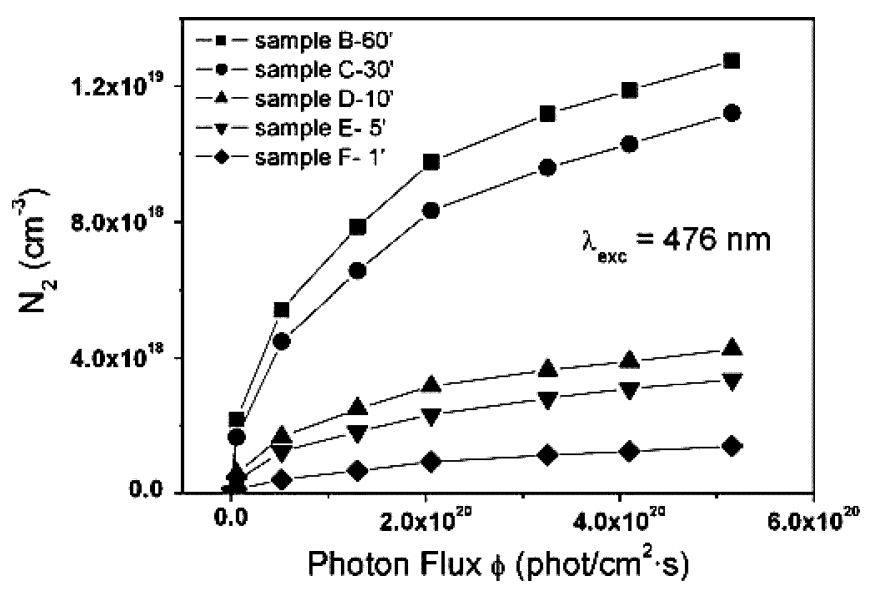

Fig. 8. Concentration of $\mathrm{Er}^{3+}$ in the first excited state for 476-nm excitation.

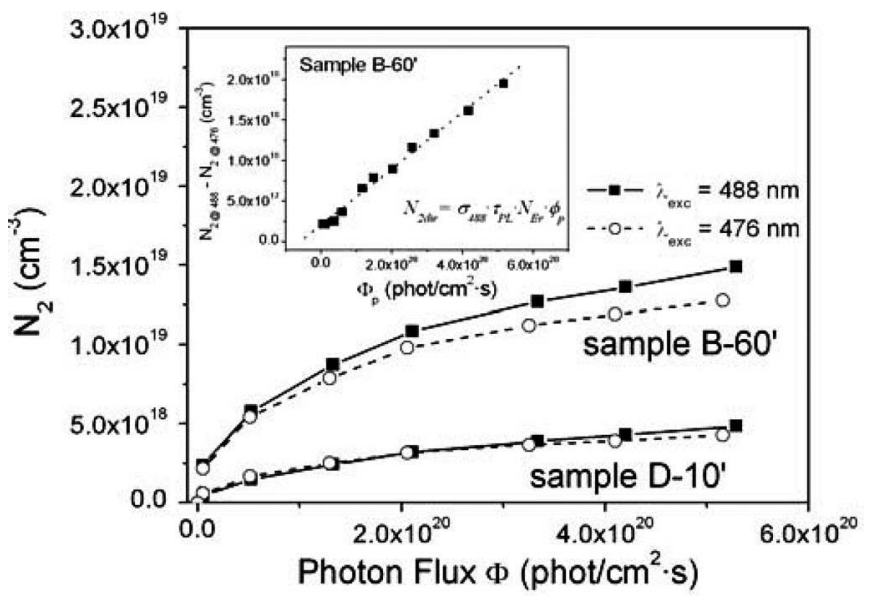

Fig. 9. Population of $\mathrm{Er}^{3+}$ first excited level in samples B-60' and D-10' under resonant $(488 \mathrm{~nm})$ and nonresonant $(476 \mathrm{~nm})$ pumping. The dependence on pump power of the population of $\mathrm{Er}^{3+}$ ions excited directly for sample B- $60^{\prime}$ are shown (inset).

mation of the maximum fraction of excitable $\mathrm{Er}^{3+}$. It is found to be $3 \times 10^{19} \mathrm{at} / \mathrm{cm}^{3}$, which corresponds to $7 \%$ of the Er in the sample.

Three explanations can be given for the low amount of excited Er: either most of the erbium is not active, or $\mathrm{Si}-\mathrm{nc}$ is unable to excite a greater percentage of erbium, or the $\mathrm{Er}^{3+}$ luminescence is quenched by some nonlinear effects. The second hypothesis draws from the fact that the coupling between the $\mathrm{Si}-\mathrm{nc}$ and $\mathrm{Er}^{3+}$ depends on the spatial distribution of $\mathrm{Er}^{3+}$ within the dielectrics and, in particular, on the $\mathrm{Si}-\mathrm{nc} / \mathrm{Er}^{3+}$ mutual distance.

Let us first address the density of optically active erbium. To this end, we measured the $\mathrm{Er}^{3+}$ luminescence under 488-nm excitation. The 488-nm line is partially resonant with the transition between the $\mathrm{Er}^{3+}$ ground state and level $\mathrm{F}_{7 / 2}$ transition characterized by an absorption cross section of $10^{-21} \mathrm{~cm}^{2}$ [4].

Fig. 9 shows the excited $\mathrm{Er}^{3+}$ density under resonant and nonresonant excitation for samples $\mathrm{B}-60^{\prime}$ and $\mathrm{D}-10^{\prime}$, the results being very similar for other samples. While $\mathrm{N}$ tends to saturate under high nonresonant pumping, it keeps growing linearly when it is resonantly excited. This is observed in all the 
samples, and it leads to the conclusion that, while the indirect transfer from Si-nc saturates at some points, $\mathrm{Er}^{3+}$ can still be excited directly by the 488 -nm line.

If we assume that no difference exists in the fraction of $\mathrm{Er}^{3+}$ excited through a Si-nc-mediated process when resonant or nonresonant pumping is used, we can determine the concentration of optically active $\mathrm{Er}^{3+}$. In fact, the difference between the number of excited Er ions for resonant $\left(N_{488}\right)$ and nonresonant $\left(N_{476}\right)$ excitation is equal to the amount of directly excited $\mathrm{Er}^{3+}$

$$
N_{488}-N_{476} \approx N_{\mathrm{Er}} \sigma_{488} \tau_{\mathrm{PL}} \phi .
$$

This calculation was performed on various samples, with the result that $N_{488}-N_{476}$ does indeed have a linear dependence on $\phi$ for each sample (Fig. 9, inset). The values of $N_{\mathrm{Er}}$ estimated from the slopes are, within the error bar, equal to those measured by RBS. As a typical example, the difference is shown in the inset of Fig. 9 for sample B-60', where an erbium concentration of $6 \pm 3 \times 10^{20} \mathrm{~cm}^{-3}$ could be estimated. These results show that: 1) in no case we are underestimating the concentration of excited $\mathrm{Er}^{3+}$, thereby confirming the validity of our procedures and 2) most of the $\mathrm{Er}^{3+}$ ions in the samples are optically active. Therefore, the low fraction of $\mathrm{Er}^{3+}$ that is excited in our experiments can be attributed to the fact that either the Si-nc cannot excite all the $\mathrm{Er}^{3+}$ or the $\mathrm{Er}^{3+}$ emission is quenched due to nonlinear processes such as Auger de-excitation or cooperative up-conversion.

Let us concentrate hereafter on the possible inability of Si-nc to excite all the $\mathrm{Er}^{3+}$ ions. On the one hand, this can be due to a low $\mathrm{Si}-\mathrm{nc} / \mathrm{Er}^{3+}$ coupling, which is supported by the recent Er segregation data of [28]. In this paper, it was reported that when a high Er concentration is used, a significant part of the $\mathrm{Er}^{3+}$ ions segregates into regions with low Si content where the distance with Si-nc gets too large for the excitation transfer to be effective. A detailed modeling addressing this problem can be found in [29], where a distance-dependent interaction is considered to explain the low amount of $\mathrm{Er}$ ions excited through Si-nc. On the other hand, the low excited Er fraction can also be due to a photon flux dependence of the effective excitation cross sections of $\mathrm{Er}^{3+}$. Indeed, in [11], it was shown that confined carrier absorption and Auger recombination turns off the coupling among Er and Si-nc.

\section{Up-Conversion}

Fig. 10 shows the pump-power dependence of the luminescence $\mathrm{Er}^{3+}$ lifetimes at the nonresonant wavelength of $476 \mathrm{~nm}$. A strong decrease of the lifetime is observed in all three samples. This decrease in the lifetimes can be interpreted as being due to up-conversion, a mechanism for which an Er ion de-excites nonradiatively giving its energy to another Er ions close by. The up-conversion coefficient $C_{\mathrm{up}}$ can be determined through the relation

$$
\frac{1}{\tau_{\mathrm{PL}}}=\frac{1}{\tau_{0}}+C_{\mathrm{up}} N
$$

From the fit of the data, the up-conversion coefficients between $2 \times 10^{-17} \mathrm{~cm}^{3} \cdot \mathrm{s}^{-1}\left(\right.$ sample B-60'), $5.5 \times 10^{-17} \mathrm{~cm}^{3} \cdot \mathrm{s}^{-1}$

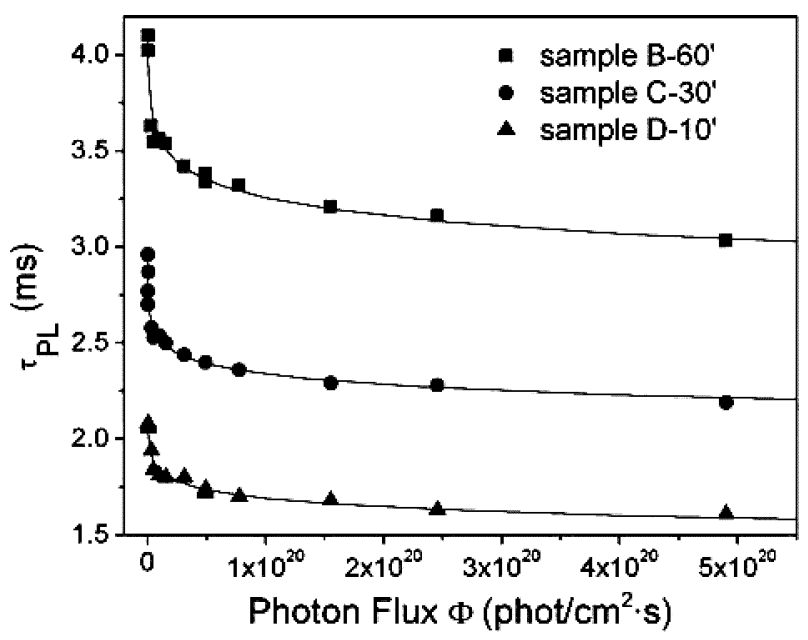

Fig. 10. Dependence of lifetimes on pump power for samples B-60', C-30', and $\mathrm{D}-10^{\prime}$ for 476-nm excitation.

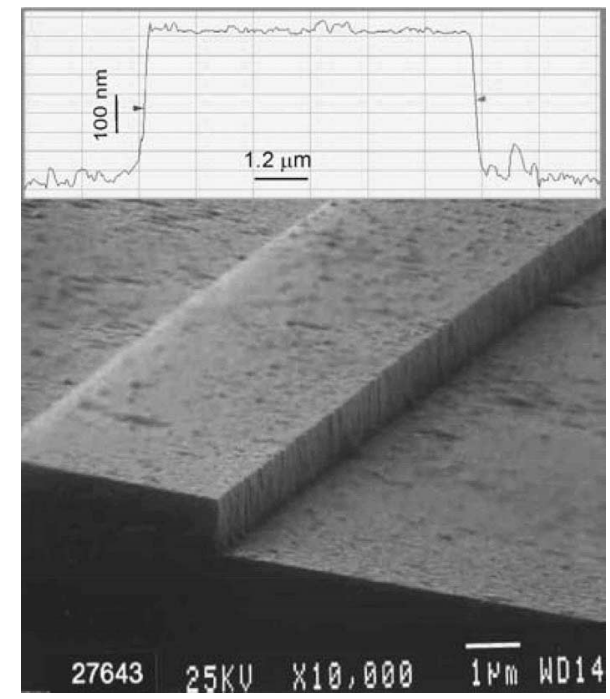

Fig. 11. Rib-loaded waveguide: SEM image and AFM profile.

(sample C-30'), and $8 \times 10^{-17} \mathrm{~cm}^{3} \cdot \mathrm{s}^{-1}$ (sample D-10') can be estimated [23].

\section{RIB-LOADED WAVEGUIDES}

Starting from the slab waveguides, a series of twodimensional (2-D) rectangular waveguides have been fabricated. Optical lithography and reactive ion etching have been used to define rib-loaded waveguides. The photolithographic mask used for waveguide definition consisted of approximately 500 lines, each 4-cm long, with rib widths between 3.5 and $12 \mu \mathrm{m}$. Scanning electron microscopy (SEM) and atomic force microscopy (AFM) have been used to characterize the rib profile as well as the waveguide roughness due to etching, and to measure the rib width (Fig. 11).

Table II shows the waveguide parameters together with the calculated confinement factor $\Gamma$ of the fundamental optical mode. The choice of the largest rectangular structures available strongly reduces scattering losses due to irregularity of 
TABLE II

WAVEGUIDE PARAMETERS

\begin{tabular}{ccccccc}
\hline Sample & $\begin{array}{c}\text { Core } \\
\text { layer } \\
\text { thickness } \\
\text { (nm) }\end{array}$ & $\begin{array}{c}\text { Etching } \\
\text { depth } \\
(\mathrm{nm})\end{array}$ & $\begin{array}{c}\mathrm{SiO}_{2} \\
\text { top } \\
\text { cladding } \\
\text { thickness } \\
(\mathrm{nm})\end{array}$ & $\begin{array}{c}\text { Length } \\
\mathrm{L} \\
(\mathrm{cm})\end{array}$ & $\begin{array}{c}\text { Rib } \\
\text { Width } \\
(\mathrm{mm})\end{array}$ & $\begin{array}{c}\text { Confinement } \\
\text { factor } \\
\Gamma\end{array}$ \\
\hline $\mathrm{A}-240$ & 750 & 900 & 1000 & 1.7 & 7.2 & $0.66 \pm 0.02$ \\
$\mathrm{~B}-60$ & 750 & 1600 & 1800 & 3 & 7.2 & $0.51 \pm 0.02$ \\
$\mathrm{C}-30$ & 840 & 340 & 1000 & 2 & 11.5 & $0.48 \pm 0.02$ \\
$\mathrm{D}-10$ & 840 & 310 & 1000 & 1.8 & 12.1 & $0.28 \pm 0.03$ \\
$\mathrm{E}-5$ & 890 & & \multicolumn{5}{c}{$\begin{array}{c}\text { not processed } \\
\text { not processed }\end{array}$} \\
F-1 & 880 & \multicolumn{6}{c}{} \\
\hline
\end{tabular}

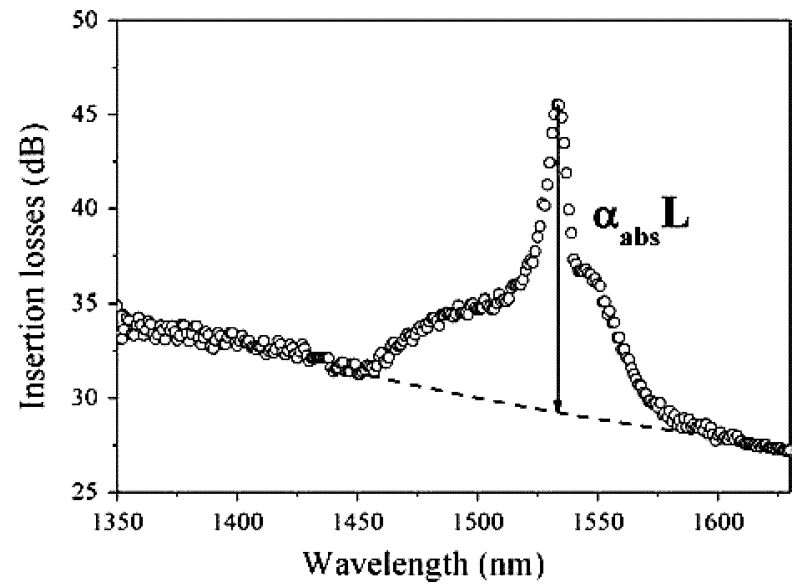

Fig. 12. Insertion loss spectrum of waveguide sample B-60' (circles). The dashed line is an estimation of the contribution due to scattering and coupling losses and serves as a baseline. The difference between the insertion loss spectrum and the baseline corresponds to the $\mathrm{Er}^{3+}$ absorption spectrum $\alpha_{\text {abs }} L$.

lateral edges of the rib structures and results in monomode optical mode. Leakage losses toward the Si substrate are minimized by the presence of a thick base layer of $\mathrm{SiO}_{2}(15 \mu \mathrm{m})$.

It is worth noting that the very low refractive index of 5and 1-min annealed waveguides (about 1.46) results in no good light confinement in the NIR range. Only waveguides annealed at $240,60,30$, and $10 \mathrm{~min}$ result in good light confinement with confinement factor $\Gamma$ from 0.66 to 0.28 , respectively.

\section{A. Optical Losses}

Optical losses measurements in the rib-loaded waveguides have been performed by butt coupling the signal from a tunable diode laser $(1.2-1.6 \mu \mathrm{m})$ through a single-mode polarizationpreserving tapered fiber moved by a piezoelectric stage. The light exiting the end facet of the waveguide was observed through a prism beam splitter, with a microscope objective $(40 \times)$ matched both to a zoom $(2 \times-12 \times)$ mounted on an InGaAs camera and to a calibrated Ge detector.

The insertion losses show the $\mathrm{Er}^{3+}$ characteristic absorption $\left(\alpha_{\text {abs }}\right)$ peak at $1534 \mathrm{~nm}$ superimposed to a background (dashed line) that decreases with the wavelength (Fig. 12). The

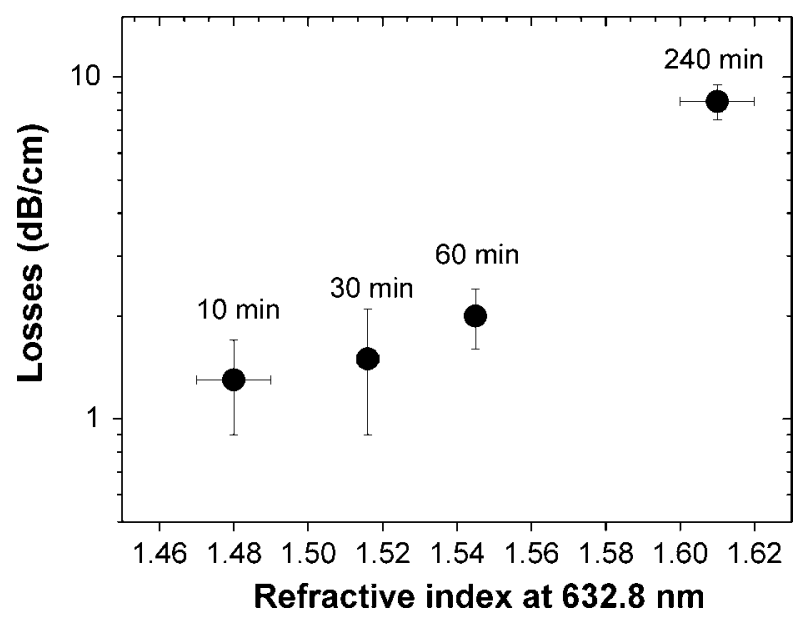

Fig. 13. Optical losses measured at $1600 \mathrm{~nm}$ as a function of the refractive index.

background is due to the coupling ( $\left.\alpha_{\text {coupling }}\right)$ and propagation $\left(\alpha_{\text {propagation }}\right)$ losses. The coupling losses can be considered constant within $1 \mathrm{~dB}$ in this wavelength range. The propagation losses at long wavelengths (i.e., at $1600 \mathrm{~nm}$, where Si-nc are transparent and the absorption of $\mathrm{Er}^{3+}$ ions is very low) can be attributed to light scattering due mainly to the waveguide roughness and, to a lower extent, to the composite structure of the core layer (Mie scattering).

In Fig. 13, the propagation losses at $1600 \mathrm{~nm}$ have been reported as a function of the refractive index. Measurements are performed at a single wavelength on a large number of ribloaded waveguides to average on misalignments and sampledependent properties. The aged samples show larger losses than the one reported here. It is clear from Fig. 13 that the losses reduce significantly (up to about $1 \mathrm{~dB} / \mathrm{cm}$ ) when the refractive index of the core layer is decreased, that is in the short annealed samples.

By subtracting the background losses, the $\mathrm{Er}^{3+}$ absorption spectrum can be reproduced and, thus, absorption cross sections $\left(\sigma_{\text {abs }}\right)$ can be deduced. In fact, $\alpha_{\text {abs }}=\Gamma \sigma_{\text {abs }} N_{\mathrm{Er}}$. As an example, for waveguide sample A-240', $\alpha_{\mathrm{abs}}=3.6 \mathrm{~dB} / \mathrm{cm}$ at $1534 \mathrm{~nm}$, which corresponds to a $\sigma_{\mathrm{abs}}=4 \pm 2 \times 10^{-21} \mathrm{~cm}^{2}$. This value is the same as that for $\mathrm{Er}^{3+}$ in pure silica, i.e., $4 \times 10^{-21} \mathrm{~cm}^{2}$ [30], thus, no effects due to the presence of the Si-nc are observed as claimed in [10] (claims revised in [31]). However, a clear increase of $\sigma_{\text {abs }}$ can be observed with a decrease in the refractive index $n$ (Fig. 14).

At first sight these results seem to contradict other experimental findings of an increase in the transition rate when the refractive index of the material increases [32]. However, this is true when the emission/absorption cross section of $\mathrm{Er}^{3+}$ is constant, i.e., when only mean field corrections apply due to composition variations, which lead to a change in the refractive index $n$. In our waveguides, we observed both a variation of the composition of the dielectric, which is reflected in a variation of $n$ and a variation of the local $\mathrm{Er}^{3+}$ environment, which is reflected in a line-shape variation of the $\mathrm{Er}^{3+}$-related optical transitions [26]. 


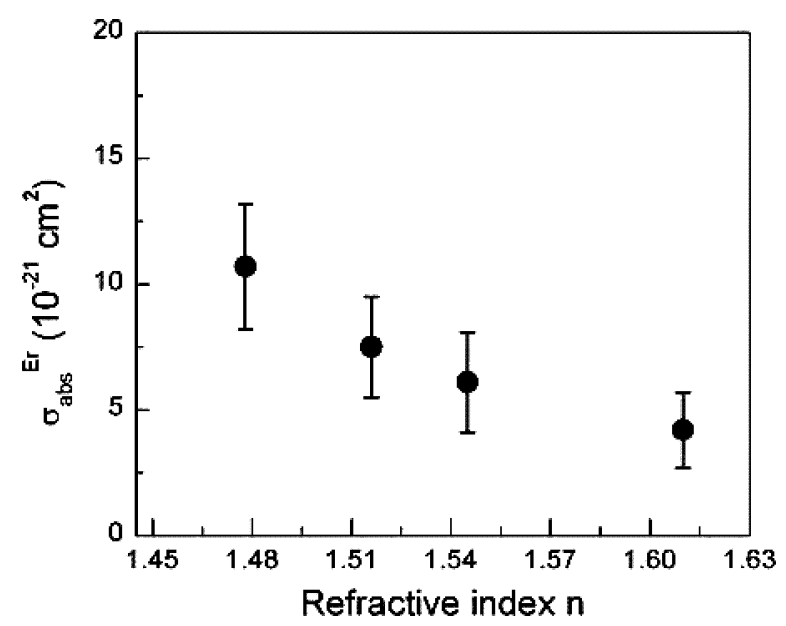

Fig. 14. $\mathrm{Er}^{3+}$ absorption cross section $\sigma_{\mathrm{abs}}$ as a function of the refractive index $n$.

\section{B. Pump and Probe Measurements}

Internal gain measurements have been performed by the pump and probe experiments. We have used two different light sources to act as probes: a tunable laser $(1.5-1.6 \mu \mathrm{m})$ that can cover a large part of the ${ }^{4} I_{13 / 2} \rightarrow{ }^{4} I_{15 / 2}$ transition (peaked at $1535 \mathrm{~nm}$ ), where the amplification effects should take part and a diode laser operating at $1310 \mathrm{~nm}$, well away from transitions related to the $\mathrm{Er}^{3+}$ ions. The probe beam was butt-coupled into the rib-loaded waveguides. The pump source was a Millenia laser $(532 \mathrm{~nm})$ or an Ar laser (488 and $476 \mathrm{~nm}$ ) focused on the waveguide surface into a $100-\mu \mathrm{m}$ wide and $1-\mathrm{cm}$ long strip by means of a cylindrical lens. The alignment of the pump with the rib-loaded waveguide was checked by two cameras for side and top observations. In order to eliminate diffused light and amplified spontaneous emission in the detection, the probe signal was chopped $(10 \mathrm{kHz})$ and then measured through a lock-in connected to a computer.

We measured the ratio of the transmitted probe light intensity when the pump beam was on the waveguide, i.e., $I_{\mathrm{P} \& \mathrm{P}}$, and when no pump beam was present, i.e., $I_{\mathrm{P}}$. Let us consider signal enhancement $\mathrm{SE}=I_{\mathrm{P} \& \mathrm{P}} / I_{\mathrm{P}}$. By using an effective two-level system [33] $\mathrm{SE}=\exp \left(2 \sigma_{\mathrm{em}} N \Gamma L\right)$, where $\sigma_{\mathrm{em}}$ is the $\mathrm{Er}^{3+}$ emission cross section and $L$ is the pumped waveguide length. We will define the internal gain coefficient as $g\left(\mathrm{~cm}^{-1}\right)=\sigma_{\mathrm{em}} N \Gamma$.

In Fig. 15, we report as a function of the pump power the signal enhancement at $1310 \mathrm{~nm}$, where $\mathrm{Er}^{3+}$ is transparent. The SE decreases with increasing pump power. The probe beam is strongly absorbed. This is attributed to confined carrier absorption where the probe photons are absorbed by pump-excited carriers confined in Si-nc. The dynamics of this effect (Fig. 15, inset) is surprisingly slow (few tens of seconds).

These long times cannot be explained by the lifetime of excitons in Si-nc, which is of the order of tens of microseconds. The explanation can be found either to excitons that are formed by electrons and holes separated by a large distance [6] or to the carrier trap associated with nanoclusters, as recently found by Forcales et al. [34].

Confined carrier absorption not only introduces a new loss mechanism on the probe signal but turns off the Si-nc-mediated

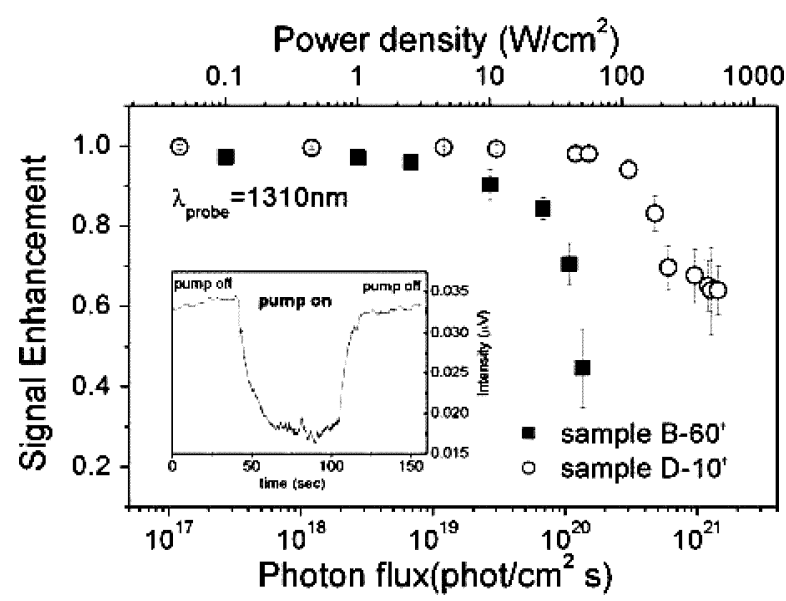

Fig. 15. Signal enhancement as a function of 532-nm photon flux when using a $1310-\mathrm{nm}$ probe. Black squares correspond to sample B-60' while empty circles correspond to sample D-10'. The temporal measurement when the pump is off and on at a certain photon flux is shown (inset).

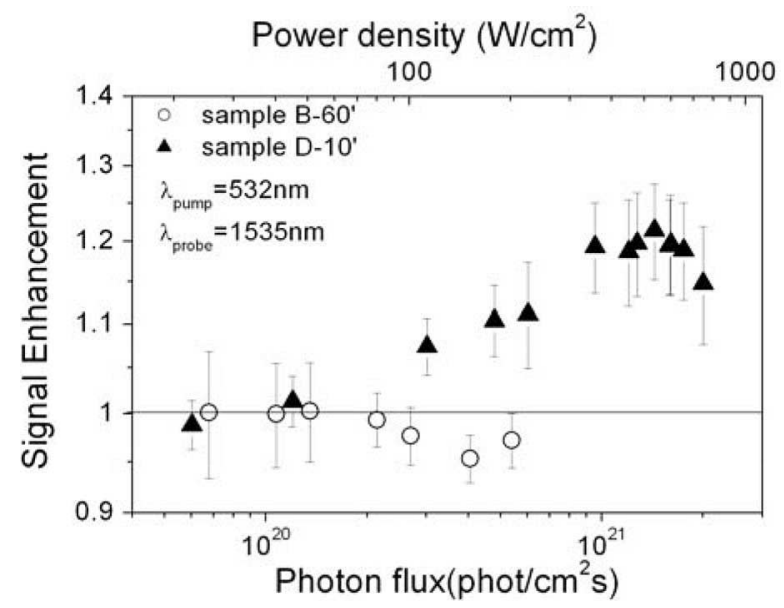

Fig. 16. Measured signal enhancement using a 1535-nm probe for sample B-60' (circles) and sample D-10' (triangles). The pump wavelength was $532 \mathrm{~nm}$.

excitation mechanism of $\mathrm{Er}^{3+}$ [11]. When decreasing the annealing time from $60^{\prime}$ to $10^{\prime}$ reducing both the size and probably also the distance among $\mathrm{Si}-\mathrm{nc}$, this detrimental effect is diminished. In fact, Fig. 15 shows that for sample D-10', the SE decrease occurs at a higher photon flux with respect to sample B- $60^{\prime}$.

To look for amplification, a probe signal at $1535 \mathrm{~nm}$ should be used. As shown in Fig. 16, the SE for sample B-60' is constant at low pump flux and decreases at high pump flux. The extent of the decrease is low and the typical flux for the onset of absorption is higher than that reported in Fig. 15.

More interestingly, in the waveguide D-10', where confined carrier absorption is minimized, there is an enhanced SE up to a maximum of $1.22(0.43 \mathrm{~dB} / \mathrm{cm})$ using moderated density powers (hundreds of watts per square centimeter). Over a critical pump-power value $\left(600 \mathrm{~W} / \mathrm{cm}^{2}\right)$, the $\mathrm{SE}$ decreases. This is due to competing loss mechanisms such as confined carrier absorption, to the reduction of the effective excitation of $\mathrm{Er}^{3+}$ via $\mathrm{Si}-\mathrm{nc}$ 


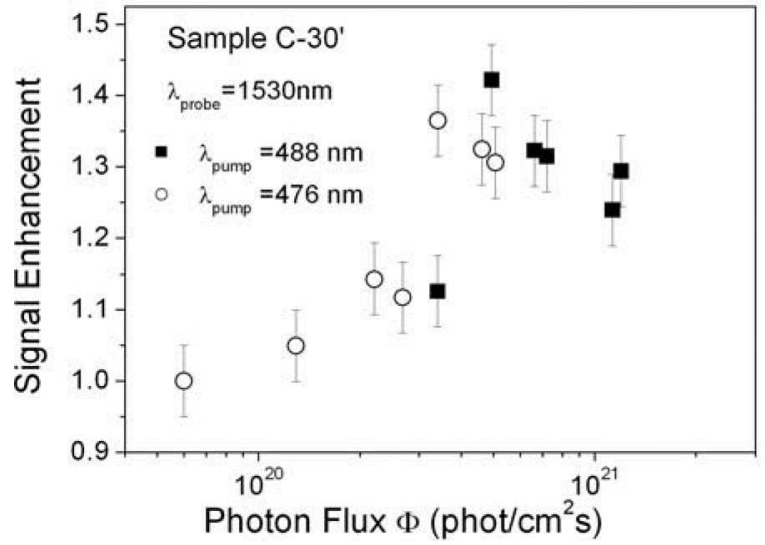

Fig. 17. Signal enhancement versus pump power for excitation lines 488 and $476 \mathrm{~nm}$ in sample C-30'.

caused by pump-power-dependent nonradiative recombinations in Si-nc (Auger and confined carrier absorption), and due to the onset of $\mathrm{Er}^{3+}$ nonradiative recombination mechanisms such as up-conversion or Auger de-excitation. Again comparing the waveguide B-60' and D-10' even though it was shown in Fig. 8 that the density of excitable $\mathrm{Er}^{3+}$ ions is three times in sample B- $60^{\prime}$ than in sample D-10', it is clear from these results that the weaker confined carrier absorption and the increased emission cross section [26] largely compensate for this difference and allow the measure of $\mathrm{SE}>1$ in waveguide $\mathrm{D}-10^{\prime}$.

In Fig. 17, the signal enhancement of sample C- $30^{\prime}$ is reported for two different excitation wavelengths, 488 and $476 \mathrm{~nm}$, which are resonant and nonresonant with $\mathrm{Er}^{3+}$ internal transitions, respectively. The probe wavelength was $1530 \mathrm{~nm}$. It was found that both lines gave a maximum SE of 1.4 at a pump flux of $5 \times 10^{20} \mathrm{ph} / \mathrm{cm}^{2} \cdot \mathrm{s}$, thus, suggesting that at these photon fluxes the $\mathrm{Er}^{3+}$ excitation is mediated by Si-nc, while the direct $\mathrm{Er}^{3+}$ excitation is negligible. The larger SE of sample C-30' (about 1.35 against 1.08 of sample D- $10^{\prime}$ at $2 \times 10^{20} \mathrm{ph} / \mathrm{cm}^{2} \cdot \mathrm{s}$ ) is to be attributed in part to the higher absorption cross section of Si-nc at $476 \mathrm{~nm}$ than at $532 \mathrm{~nm}$, and in part to the higher excitable $\mathrm{Er}^{3+}$ concentration (Fig. 8). Moreover, it has been shown that the up-conversion is weaker in sample C- $30^{\prime}$ than in sample D-10'.

\section{CONCLUSION}

In this paper, we have reported the investigation of the effects of changing dielectrics on the recombination of $\mathrm{Er}^{3+}$ coupled to Si-nc. Amplification studies have also been carried out with clear indications of signal enhancement. We decided to change the $\mathrm{Er}^{3+}$ environment by keeping the excess $\mathrm{Si}$ content constant while performing annealing treatment at a fixed temperature for various durations. In this way, it was possible to relate the annealing time with the clustering of $\mathrm{Si}$ into Si-nc of growing sizes. Only at the longest annealing time, the phase separation between $\mathrm{SiO}_{2}$ and $\mathrm{Si}$ seems to be completed. At intermediate annealing time, a situation emerges where both a nonstoichiometric $\mathrm{SiO}_{x}$ and small $\mathrm{Si}-\mathrm{nc}$ are present. All these variations can be recognized in the refractive index values that increase when the annealing time lengthens.

The variations of the composition of the dielectrics have a strong influence on the recombination dynamics of $\mathrm{Er}^{3+}$. In particular, increasing the annealing time: 1 ) increases the effective excitation cross sections; 2) decreases the absorption cross sections; 3 ) decreases the emission cross sections; 4) increases the radiative lifetimes; 5) decreases the up-conversion coefficients; and finally, 6) increases the maximum excitable fraction of $\mathrm{Er}^{3+}$.

Also, the signal propagation in ridge-loaded waveguides is affected by the annealing time. Indeed the propagation losses have been found to increase. Moreover, confined carrier absorption within the Si nanocluster, which is a considerable pumppower-dependent loss mechanism, increases with the formation of larger Si-nc. Confined carrier absorption is not only a loss mechanism but it also influences the coupling of Si-nc with the $\mathrm{Er}^{3+}$ ions.

Hence, intermediate annealing time seems to emerge as a choice for this set of processing parameters, if one aims at the amplification of the waveguide. In fact, decreasing the annealing time and, thus, the refractive index the propagation losses are reduced but, in contrast, the number of excitable $\mathrm{Er}^{3+}$ ions via Si-nc are decreased too (Fig. 9). Moreover, the up-conversion increases with reducing the annealing time. So the optimum choice is an intermediate value, where a maximum SE of 1.35 is measured.

This paper has shown that to optimize EDWA based on the coupled Si-nc/Er ${ }^{3+}$ system, a lot of work still remains to be done in terms of optimizing the material properties and waveguide geometries, in order to reduce the parasitic effects (confined carrier absorption, up-conversion, Auger), to enhance the excitable Er fraction via Si-nc and to achieve a net optical gain.

\section{ACKNOWLEDGMENT}

The authors would like to thank L. Cognolato from Agilent, Turin, Italy, and G. Pucker from ITC-IRST, Trento, Italy, for waveguide processing, and E. Borsella from ENEA, Frascati, Rome, Italy, for scientific discussions.

\section{REFERENCES}

[1] A. Polman and F. C. J. M. van Veggel, "Broadband sensitizers for erbiumdoped planar optical amplifiers: Review," J. Opt. Soc. Amer. B, Opt. Phys., vol. 21, pp. 871-892, May 2004.

[2] F. Priolo, G. Franzò, D. Pacifici, V. Vinciguerra, F. Iacona, and A. Irrera, "Role of the energy transfer in the optical properties of undoped and Erdoped interacting Si nanocrystals," J. Appl. Phys., vol. 89, pp. 264-272, Jan. 2001.

[3] D. Pacifici, G. Franzò, F. Priolo, F. Iacona, and L. D. Negro, "Modeling and perspectives of the Si nanocrystals-Er interaction for optical amplification," Phys. Rev. B, Condens. Matter, vol. 67, pp. 245301-1-245301-3, Jun. 2003.

[4] A. J. Kenyon, C. E. Chryssou, C. W. Pitt, T. Shimizu-Iwayama, D. E. Hole, N. Sharma, and C. J. Humphreys, "Luminescence from erbium-doped silicon nanocrystals in silica: Excitation mechanisms," J. Appl. Phys., vol. 91, pp. 367-374, Jan. 2002.

[5] F. Iacona, D. Pacifici, A. Irrera, M. Miritello, G. Franzò, F. Priolo, D. Sanfilippo, G. Di Stefano, and P. G. Fallica, "Electroluminescence at $1.54 \mu \mathrm{m}$ in Er-doped Si-nanocluster-based devices," Appl. Phys. Lett., vol. 81, pp. 3242-3244, Oct. 2002. 
[6] P. G. Kik and A. Polman, "Towards an Er-doped Si nanocrystals sensitized waveguide laser - the thin line between gain and loss," in Towards the First Silicon Laser, vol. 93, (NATO Science Series II, Mathematics, Physics, and Chemistry), L. Pavesi, S. Gaponenko, and L. D. Negro, Eds. Dordrecht, The Netherlands: Kluwer, 2003, pp. 383-400.

[7] J. H. Shin, H. S. Han, and S. Y. Seo, "Optical gain using nanocrystals sensitized erbium," in Towards the First Silicon Laser, vol. 93, (NATO Science Series II, Mathematics, Physics, and Chemistry), L. Pavesi, S. Gaponenko, and L. D. Negro, Eds. Dordrecht, The Netherlands: Kluwer, 2003, pp. 401420 .

[8] J. Lee, J. H. Shin, and N. Park, "Optical gain at $1.5 \mu \mathrm{m}$ in nanocrystals Sisensitized Er-doped silica waveguide using top-pumping $470 \mathrm{~nm}$ LEDs," J. Lightw. Technol., vol. 23, no. 1, pp. 19-25, Jan. 2005.

[9] W. H. Loh and A. J. Kenyon, "Excited state absorption in the Si nanocluster-Er material system," IEEE Photon. Technol. Lett., vol. 18, no. 1, pp. 289-291, Jan. 2006.

[10] P. G. Kik and A. Polman, "Gain limiting processes in Er-doped Si nanocrystal waveguides in $\mathrm{SiO}_{2}$, , J. Appl. Phys., vol. 91, pp. 534-536, Jan. 2002.

[11] N. Daldosso, D. Navarro-Urrios, F. Gourbilleau, M. Carrada, R. Rizk, C. García, P. Pellegrino, B. Garrido, and L. Cognolato, "Absorption cross section and signal enhancement in Er-doped Si-nanocluster rib loaded waveguides," Appl. Phys. Lett., vol. 87, pp. 261103-1-261103-3, May 2005.

[12] M. Fujii, K. Imakita, K. Watanabe, and S. Hayashi, "Coexistence of two different energy transfer processes in $\mathrm{SiO}_{2}$ films containing Si nanocrystals and Er," J. Appl. Phys., vol. 95, pp. 272-280, Jan. 2004.

[13] D. Pacifici, L. Lanzanò, G. Franzò, F. Priolo, and F. Iacona, "Revealing the sequential nature of the Si-nanocluster-Er interaction by variable pulse duration excitation," Phys. Rev. B, Condens. Matter, vol. 72, pp. 0453491-045349-6, Jul. 2005

[14] M. Wojdak, M. Klik, M. Forcales, O. B. Gusev, T. Gregorkiewicz, D. Pacifici, G. Franzò, F. Priolo, and F. Iacona, "Sensitization of Er luminescence by Si nanoclusters," Phys. Rev. B, Condens. Matter, vol. 69, pp. 233315-1-233315-4, Jun. 2004.

[15] F. Gourbilleau, M. Levalois, C. Dufour, J. Vicens, and A. Rizk, "Optimized conditions for an enhanced coupling rate between Er ions and $\mathrm{S}$ nanoclusters for an improved 1.54- $\mu$ m emission," J. Appl. Phys., vol. 95 pp. 3717-3722, Apr. 2004.

[16] F. Gourbilleau, X. Portier, C. Ternon, P. Voivenel, R. Madelon, and R. Rizk, "Si-rich $/ \mathrm{SiO}_{2}$ nanostructured multilayers by reactive magnetron sputtering," Appl. Phys. Lett., vol. 78, pp. 3058-3060, May 2001.

[17] C. Ternon, F. Gourbilleau, X. Portier, P. Voivenel, and C. Dufour, "An original approach for the fabrication of $\mathrm{Si} / \mathrm{SiO}_{2}$ multilayers using reactive magnetron sputtering," Thin Solid Films, vol. 419, pp. 5-10, Nov. 2002.

[18] F. Gourbilleau, C. Dufour, M. Levalois, J. Vicens, R. Rizk, C. Sada, F. Enrichi, and G. Battaglin, "Room-temperature $1.54 \mu \mathrm{m}$ photoluminescence from Er-doped Si-rich silica layers obtained by reactive magnetron sputtering," J. Appl. Phys., vol. 94, pp. 3869-3874, Sep. 2003.

[19] F. Gourbilleau, R. Madelon, C. Dufour, and R. Rizk, "Fabrication and optical properties of Er-doped multilayers Si-rich $\mathrm{SiO}_{2} / \mathrm{SiO}_{2}$ : Size control, optimum Er-Si coupling and interaction distance monitoring," Opt. Mater., vol. 27, pp. 868-875, Feb. 2005.

[20] M. Carrada, F. Gourbilleau, C. Dufour, M. Levalois, and R. Rizk, "Influence of Er concentration on the emission properties of Er-doped Si-rich silica films obtained by reactive magnetron co-sputtering," Opt. Mater. vol. 27, pp. 915-919, Feb. 2005.

[21] A. M. Jayannavar and N. Kumar, "Generalization of Bruggeman's unsymmetrical effective-medium theory to a three-component composite," Phys. Rev. B, Condens. Matter, vol. 44, pp. 12014-12015, Dec. 1991.

[22] B. Abeles and J. I. Gittleman, "Composite material films: Optical properties and applications," Appl. Opt., vol. 15, pp. 2328-2338, Oct. 1976.

[23] D. Navarro-Urrios, M. Melchiorri, N. Daldosso, L. Pavesi, C. García, P. Pellegrino, B. Garrido, G. Pucker, F. Gourbilleau, and R. Rizk, "Optical losses and gain in silicon-rich silica waveguides containing $\mathrm{Er}$ ions," $J$ Lumin., vol. 121, pp. 249-255, Dec. 2006.

[24] J. A. Moreno, B. Garrido, P. Pellegrino, C. Garcia, J. Arbiol, J. R. Morante, P. Marie, F. Gourbilleau, and R. Rizk, "Size dependence of refractive index of Si nanoclusters embedded in $\mathrm{SiO}_{2}$," J. Appl. Phys., vol. 98, pp. 013523 1-013523-4, Jul. 2005

[25] M. J. A. de Dood, A. Polman, T. Zijlstra, and E. W. J. M. van der Drift, "Amorphous silicon waveguides for microphotonics," J. Appl. Phys., vol. 92, pp. 649-653, Jul. 2002.

[26] N. Daldosso, D. Navarro-Urrios, M. Melchiorri, L. Pavesi, F. Gourbilleau, and R. Rizk, "Refractive index dependence of the absorption and emission cross sections at $1.54 \mu \mathrm{m}$ of $\mathrm{Er}^{3+}$ coupled to Si nanoclusters," Appl. Phys. Lett., vol. 88, pp. 16190-1-16190-3, Apr. 2006.

[27] M. J. A. de Dood, L. H. Slooff, A. Polman, A. Moroz, and A. van Blaarderen, "Local optical density of states in $\mathrm{SiO}_{2}$ spherical microcavities: Theory and experiment," Phys. Rev. A, Gen. Phys., vol. 64, pp. 033807-1-0033807-7, Sep. 2001

[28] P. Pellegrino, B. Garrido, J. Arbiol, C. Garcia, Y. Lebour, and J. R. Morante, "Location of Er atoms with respect to Si nanoclusters in luminescent Er and Si co-implanted silicates," in Proc. Mater. Res. Soc. Symp., Warrendale, PA, 2005, vol. 832, pp. F11.4.1-F11.4.12.

[29] B. Garrido, C. García, P. Pellegrino, D. Navarro-Urrios, N. Daldosso, L. Pavesi, F. Gourbilleau, and R. Rizk, Appl. Phys. Lett., vol. 89, pp. 163103-1-163103-3, Oct. 2006.

[30] W. J. Miniscalco, "Erbium-doped glasses for fiber amplifiers at $1500 \mathrm{~nm}$," J. Lightw. Technol., vol. 9, no. 2, pp. 234-250, Feb. 1991.

[31] H. Mertens, A. Polmann, I. M. P. Aarts, W. M. M. Kessels, and M. C. M. van de Sanden, "Absence of the enhanced intra-4f transition cross section at $1.5 \mu \mathrm{m}$ of $\mathrm{Er}^{3+}$ in Si-rich $\mathrm{SiO}_{2}$," Appl. Phys. Lett., vol. 86, pp. 241109-1-241109-3, Jun. 2005.

[32] E. Snoeks, A. Lagendijk, and A. Polman, "Measuring and modifying the spontaneous emission rate of erbium near an interface," Phys. Rev. Lett., vol. 74, pp. 2459-2462, Mar. 1995.

[33] H. S. Han, S. Y. Seo, and J. H. Shin, "Optical gain at $1.54 \mu \mathrm{m}$ in erbium-doped silicon nanocluster sensitized waveguide," Appl. Phys. Lett., vol. 79, pp. 4568-4570, Dec. 2001.

[34] M. Forcales, N. J. Smith, and R. G. Elliman, "Pump and probe experiments at $1.54 \mu \mathrm{m}$ on silicon-rich silicon oxide waveguides," J. Appl. Phys., vol. 100, pp. 014902-1-014902-3, Jul. 2006.

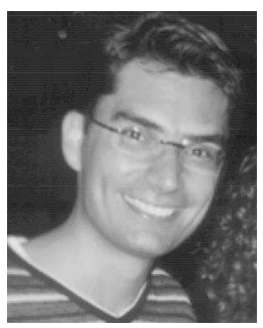

Nicola Daldosso was born in Verona, Italy, on April 6,1972 . He received the Graduate degree in physics from the University of Trento, Trento, Italy, and the $\mathrm{Ph} . \mathrm{D}$. degree in physics of matter from the Université J. Fourier, Grenoble, France, in 1997 and 2001, respectively.

During 1998-2000, he was with the Italian beamline GILDA at the European Synchrotron Radiation Facilities (ESRF), Grenoble. Since 2001, he has been with the Nanoscience Laboratory, Department of Physics, University of Trento. He is the author or coauthor of about 50 papers, coauthor of two books, and the holder of one patent. His current research interests include structural and optical properties of nanostructures materials, particularly silicon nanocrystals as well as erbiumdoped ones, and, more recently, integrated optoelectronics on silicon.

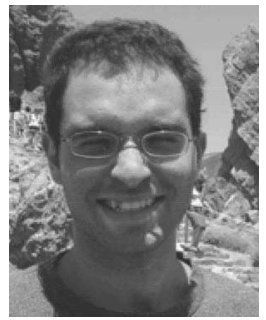

Daniel Navarro-Urrios was born in Santa Cruz de Tenerife, Spain, on October 23, 1978. He received the Graduate degree in physics from the University of La Laguna, Tenerife, Spain, in 2002. He is currently working toward the Ph.D. degree at the Nanoscience Laboratory, University of Trento, Trento, Italy.

His current research interests include the structural and optical properties of nanostructured materials.

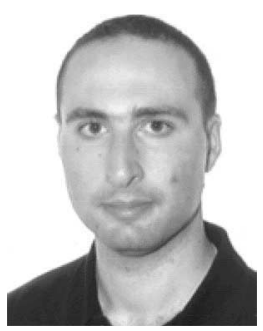

Mirko Melchiorri was born on December 27, 1978. He received the Master's degree in physics from the University of L'Aquila, L'Aquila, Italy, in 2002, and the Ph.D. degree in physics of matter from the University of Trento, Trento, Italy, in 2006.

$\mathrm{He}$ is currently with Istituto Trentino di Cultura, IRST, Trento. His current research interests include structural and optical properties of nanostructures materials and, more recently, silicon radiation detectors. 


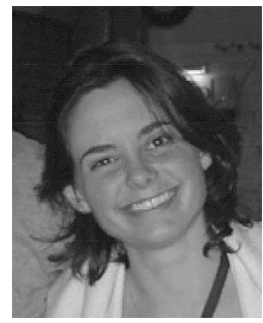

Cristina García received the Graduate and Ph.D. degrees in physics from the University of Barcelona, Barcelona, Spain, in 2001 and 2006, respectively.

Currently, she is a Scientific Collaborator in the group of Prof. B. Garrido at the University of Barcelona, Barcelona, Spain. She is the author or coauthor of about 15 papers published in international journals. Her current research interests include optical properties of nanostructured materials as well as the structural characterization.

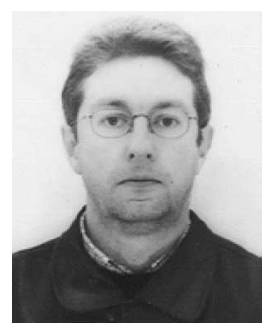

Paolo Pellegrino received the Graduate degree in physics from the University of Pavia, Pavia, Italy, and the $\mathrm{Ph} . \mathrm{D}$. degree in electronic engineering from the Royal Institute of Technology, Stockholm, Sweden, in 1996 and 2001, respectively.

Since 2002, he has been a Researcher at the University of Barcelona, Barcelona, Spain, under the "Ramon y Cajal" Spanish National Program.

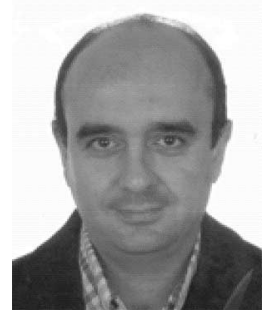

Blas Garrido received the Graduate degree in applied physics and electronics and the Ph.D. degree in microelectronics from the University of Barcelona, Barcelona, Spain, in 1989 and 1993, respectively.

Since 1995, he has been an Associate Professor in the Electronics Department at the University of Barcelona. His research has been concerned with the technology and characterization of Si-based microelectronic materials and devices for optoelectronics and photonics. He has led several EU and national projects and is the coauthor of more than 120 papers. His current research interests include thin gate dielectrics and nanostructured materials, their physics and technology at micro and nanolevel, and the fabrication of devices based on them for electronic (nanomemories), optoelectronic (Si-based light-emitting diodes and lasers), photonic (waveguide amplifiers and optical logic gates) and sensor (optochemical sensors) applications.

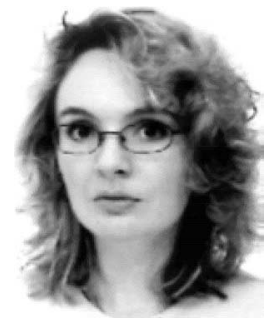

Cinzia Sada was born in 1973. She received the Graduate degree (cum laude) in physics from the University of Padova, Padova, Italy, in 1997, and the Ph.D. degree in materials science from the University of Catania, Catania, Italy, in 2001.

Since 2006, she has been a Researcher in the Physics Department at the University of Padova. She is the coauthor of more than 90 publications in international refereed journals. Her current research intrests include the characterization of structural, optical, and magnetic properties of thin films.

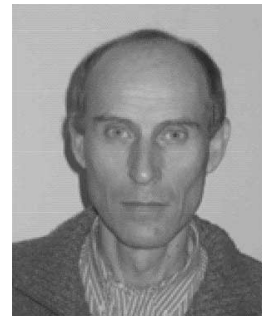

Giancarlo Battaglin was born in 1953. He received the Graduate degree in physics from the University of Padova, Padova, Italy in 1977.

Since 2000, he has been a Full Professor of physics in the Faculty of Mathematical, Physical, and Natural Sciences at the University "Ca' Foscari" of Venezia, Venice, Italy. He has also been with the Department of Physical Chemistry, University of Venezia. His research has been concerned with nuclear microanalytical techniques. He is the coauthor of more than 200 scientific papers. His current research interests include synthesis and characterization of structural, optical, magnetic, and chemical properties of thin films and layers.

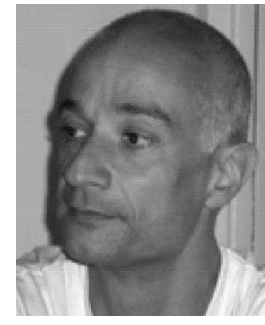

Fabrice Gourbilleau was born in 1965 . He received the Ph.D. degree in physics from the University of Caen, Caen, France, in 1993.

Since 1994, he has been in a permanent "Centre National de la Recherche Scientifique (CNRS)" position at the Structure des interfaces et Fonctionnalité des Couches Minces (SIFCOM) laboratory, Caen, France, where he is engaged in research on the fabrication and characterization of nanostructured siliconbased thin films for photonic applications. He has developed particular processes for depositing materials having specific properties. He has been engaged in several EU and national projects dealing with laser, photovoltaic, and photonics applications. He is the author or coauthor of more than 80 papers published in international journals and is the holder of one patent.

Dr. Gourbilleau is the Representative of the Nanosciences for the Region Basse Normandie and is involved in the Transfer of Technology Society for the Creation of Start-Up.

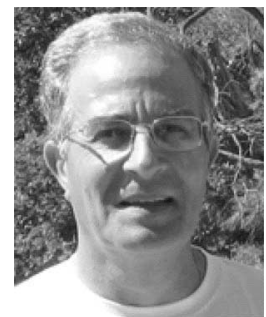

Richard Rizk received the Doctorat d'Etat degree in physics from the University of Paris (Orsay Campus), Paris, France, in 1976.

In 1986, he was with the University of Illinois at Urbana-Champaign, Urbana. He is currently the Director of Research at the Centre National de la Recherche Scientifique (CNRS) and heads the Structure des interfaces et Fonctionnalité des Couches Minces (SIFCOM) laboratory, Caen, France, and the "Integrated Nanostructures for Microelectronics and Photonics" group. His current research interests include solid-state physics covering the fields of electronic, optoelectronic, and photonic Si-based materials and devices. He is the author or coauthor of more than 130 research papers, the author of several invited papers and contributions to special issues and books, the editor of several conference proceedings, and the holder of one patent

Dr. Rizk was the recipient of the Fulbright Award in 1988.

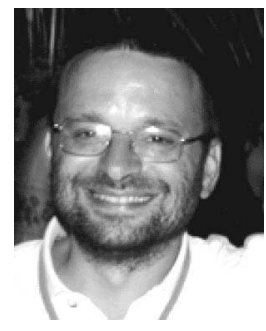

Lorenzo Pavesi was born on November 21, 1961. He received the Ph.D. degree in physics from the Ecole Polytechnique Federale, Lausanne, Switzerland, in 1990

He became an Assistant Professor in 1990, an Associate Professor in 1999, and a Full Professor in 2002, at the University of Trento, Trento, Italy, where he is currently a Professor of experimental physics. He leads the nanoscience laboratory and teaches several classes in the Science Faculty as well as the Engineering Faculty at the University of Trento. He is the founder of research activity in semiconductor optoelectronics at the University of Trento. His research has been concerned with Si-based optoelectronics, where the convergence between photonics and electronics is studied using the silicon nanostructures. He is the author or coauthor of more than 250 research papers, the author of several reviews, the editor of ten books, the author of two books, and the holder of five patents. His current research interests include active photonics devices that can be integrated in silicon using classical waveguides or novel waveguides such as those based on dynamical photonic crystals, as well as optical and biosensors. 